\title{
Karakter Agronomi Galur Padi Dihaploid Asal Kultur Antera Hasil Persilangan Three Way Cross
}

\author{
Agronomic Characters of Doubled-haploid Rice Lines from \\ Anther Culture Derived Three Way Cross Breeding
}

\author{
Mohammad Syafii ${ }^{1}$, Bambang Sapta Purwoko ${ }^{2 *}$, Iswari Saraswati Dewi ${ }^{3}$, dan Willy Bayuardi Suwarno ${ }^{2}$ \\ ${ }^{1}$ Program Studi Pemuliaan dan Bioteknologi Tanaman, Sekolah Pascasarjana, Institut Pertanian Bogor \\ ${ }^{2}$ Departemen Agronomi dan Hortikultura, Fakultas Pertanian, Institut Pertanian Bogor \\ (Bogor Agricultural University), Jl. Meranti, Kampus IPB Darmaga, Bogor 16680, Indonesia \\ ${ }^{3}$ Balai Besar Bioteknologi dan Sumber Daya Genetik Pertanian \\ Jl. Tentara Pelajar No. 3A, Cimanggu, Bogor, Indonesia
}

Diterima 1 Agustus 2017/Disetujui 1 November 2017

\begin{abstract}
Anther culture is useful tool in rice breeding. The technique shortens the time to obtain full homozygous plant in just one generation. Information related to genetic variability among the regenerants is important for further analysis including selection activities. The objective of this study was to analyze agronomic character variability and yield potential among doubled-haploid lines (DHO) derived from anther culture. This study was carried out in Center for Agricultural Biotechnology and Genetic Resources Research and Development (BB Biogen) from October 2016 to February 2017. The experiment was arranged in randomized complete block design (RCBD) with three replications. Forty eight doubled haploid lines derived from anther culture and three check varieties were evaluated. The results showed high genetic variability as well as broad sense heritability (more than 90\%) for all variables tested. Several lines showed superior agronomic characters compared to check (Ciherang, Inpari 18, Inpago 10). Anther culture could generate high genetic variability for further selection.
\end{abstract}

Keywords: anther culture, broad sense heritability, haploid technology

\section{ABSTRAK}

Kultur antera merupakan teknikyang bermanfaat dalam kegiatan pemuliaan tanaman padi, untuk mempersingkat waktu mendapatkan tanaman homozigot penuh hanya dalam satu generasi. Informasi terkait keragaman genetik tanaman hasil kultur antera yang dihasilkan sangat penting untuk pengujian berikutnya termasuk kegiatan seleksi. Penelitian ini bertujuan untuk mengetahui keragaman karakter agronomi dan potensi hasil dari galur dihaploid generasi pertama (DH0) asal kultur antera. Percobaan dilakukan di rumah kaca Balai Besar Penelitian dan Pengembangan Bioteknologi dan Sumber Daya Genetik Pertanian (BB Biogen) pada bulan Oktober 2016 sampai Februari 2017. Penelitian ini menggunakan rancangan acak kelompok lengkap teracak (RKLT) dengan tiga ulangan. Sebanyak 48 galur yang diuji adalah galur dihaploid DHO asal kultur antera diuji pada penelitian ini dan tiga varietas pembanding. Hasil penelitian menunjukkan keragaman genetik yang tinggi dan heritabilitas arti luas tinggi (lebih dari 90\%) pada semua variabel pengujian. Beberapa galur memiliki karakter agronomi yang lebih baik dibandingkan pembanding (Ciherang, Inpari 18, Inpago 10). Hasil ini membuktikan bahwa kultur antera mampu menghasilkan galur dengan keragaman genetik tinggi dan memiliki karakter agronomi baik.

Kata kunci: heritabilitas arti luas, kultur antera, teknologi haploid

\section{PENDAHULUAN}

Produksi padi sebagai salah satu pangan pokok penting yang dikonsumsi lebih dari separuh penduduk dunia (FAO, 2014), dihadapkan pada tantangan pertumbuhan penduduk

\footnotetext{
* Penulis untuk korespondensi. e-mail: bspurwoko@apps.ipb. ac.id
}

dan perubahan iklim. Sekitar $90 \%$ padi ditanam di Asia (mendekati 640 juta ton), produsen utamanya adalah China (Seck et al., 2012). Pengaruh perubahan iklim memunculkan lingkungan stres baru yang berdampak pada penurunan produksi, sehingga pengembangan padi toleran perubahan iklim menjadi penting (Leung et al., 2015).

Keragaman genetik sangat esensial dalam perakitan varietas padi yang toleran terhadap kondisi iklim kurang 
menguntungkan, dan secara bersamaan memiliki produksi tinggi dan kaya nutrisi (Leung et al., 2015). Informasi keragaman genetik sangat berguna untuk identifikasi dan seleksi tetua dalam kegiatan pemuliaan (Anupam et al., 2017). Pendekatan kegiatan pemuliaan yang tepat dapat menentukan keberhasilan dalam menjawab tantangan tersebut. Bradshaw (2017) mengemukakan bahwa cara paling cepat untuk menghasilkan galur inbrida melalui persilangan buatan adalah melalui produksi tanaman dihaploid.

Padi merupakan salah satu tanaman serealia yang telah berhasil dikembangkan melalui teknik kultur antera untuk mendapatkan galur dihaploid. Teknik ini dapat diadopsi untuk kegiatan pemuliaan tanaman padi, meskipun baru terbatas pada padi japonica (Silva, 2010). Protokol kultur antera yang dapat digunakan untuk mengatasi berbagai hambatan pengembangan teknik ini pada padi indica telah diperoleh (Dewi dan Purwoko, 2012), sehingga teknik kultur antera dapat digunakan dalam kegiatan pemuliaan padi indica.

Selain unggul dalam mempercepat kegiatan pemuliaan tanaman (Mishra dan Rao, 2016), kultur antera juga dapat menghasilkan karakter baru yang sebelumnya belum pernah muncul. Dewi et al. (2009) menemukan karakter baru terkait dengan bulu pada tanaman padi yang tidak dimiliki oleh kedua tetua persilangan yang digunakan. Karakter baru yang muncul dapat berupa karakter menguntungkan seperti ketahanan terhadap cekaman biotik maupun abiotik, sehingga meski galur tersebut tidak terpilih dalam kegiatan seleksi namun dapat bermanfaat sebagai tetua untuk perakitan galur berikutnya.

Pada perakitan galur padi indica toleran kekeringan berdaya hasil tinggi menggunakan teknik kultur antera, Gunarsih et al. (2016) melaporkan daya induksi kalus hanya berkisar 3.2-10.2. Perbaikan daya kultur dapat dilakukan dengan menambahkan genotipe yang diketahui memiliki daya kultur tinggi. Gadjah Mungkur merupakan varietas yang diketahui toleran kekeringan serta memiliki daya kultur yang tinggi (Sasmita, 2001). Penambahan Gadjah Mungkur sebagai salah satu tetua melalui persilangan three way cross ini telah berhasil meningkatkan secara signifikan daya kultur dan menghasilkan 693 tanaman hijau, sebanyak 275 tanaman diantaranya merupakan dihaploid (Dewi et al., 2017). Tanaman dihaploid dari kultur antera ini merupakan tanaman homozigot penuh hasil penggandaan kromosom secara spontan, sehingga tidak akan mengalami segregasi pada generasi berikutnya.

Galur-galur dihaploid generasi pertama (DH0) asal kultur antera sangat bervariasi (Herawati et al., 2010). Lebih lanjut Mishra et al. (2015) mengemukakan bahwa segregasi dua sifat tetua diantara tanaman hasil kultur antera sudah cukup besar sehingga dapat dilakukan seleksi untuk karakter penting seperti umur tanaman, tinggi tanaman, panjang malai, jumlah anakan, hasil, dan karakter bulir padi. Kegiatan karakterisasi galur-galur hasil kultur antera perlu dilakukan untuk mengetahui keragaman galur tersebut, baik pada karakter agronomi ataupun hasil. Penelitian ini bertujuan untuk mengetahui karakter agronomi, keragaman, dan hasil dari galur DH0 asal kultur antera.

\section{BAHAN DAN METODE}

Percobaan dilakukan pada bulan Oktober 2016 sampai Februari 2017 di rumah kaca Balai Besar Penelitian dan Pengembangan Bioteknologi dan Sumber Daya Genetik Pertanian (BB Biogen) menggunakan rancangan kelompok lengkap teracak (RKLT) dengan tiga ulangan. Bahan yang digunakan dalam penelitian ini adalah 48 galur dihaploid hasil kultur antera persilangan three way cross yaitu 1) DR7 = Inpari 18/B12825E-TB-1-25//Gajah Mungkur, 2) DR8 = Inpari 18/IR87795-14-11-b-ski-12//Gajah Mungkur, 3) DR9 = Inpari 18/IR83140-B-11-B//Gajah Mungkur, 4) DR10 = Inpari 22/IR87705-14-11-B-SKI-12//Gajah Mungkur, 5) DR11 = Inpari 22/IR83140-B-11-B//Gajah Mungkur, 6) DR12 = Inpago 8/B12825E-TB-1-25//Gajah Mungkur, dan tiga varietas pembanding yaitu Ciherang, Inpari 18, dan Inpago 10. Tetua dalam persilangan tersebut antara lain adalah dua varietas unggul baru padi sawah (Inpari 18 dan Inpari 22), varietas unggul baru padi gogo (Inpago 10), satu galur dan tiga galur toleran kekeringan, serta varietas tahan kekeringan sekaligus memiliki daya kultur tinggi (Gadjah Mungkur).

Benih disemai dalam bak semai berisi lumpur, setelah 21 hari bibit kemudian dipindah tanam ke dalam pot berisi tanah sawah, sebanyak 1 bibit per pot. Tanaman dipupuk dengan dosis $200 \mathrm{~kg} \mathrm{ha}^{-1}$ ( $5 \mathrm{~g}$ per pot) Urea, $100 \mathrm{~kg} \mathrm{ha}^{-1}(2.5$ g per pot) SP36, dan $100 \mathrm{~kg} \mathrm{ha}^{-1}$ (5 g per pot) $\mathrm{KCl}$ (Herawati et al. 2010). Pemeliharaan dilakukan berdasarkan budidaya padi sawah.

Pengamatan yang dilakukan meliputi tinggi generatif, jumlah anakan, jumlah anakan produktif, panjang malai, umur berbunga, umur panen, jumlah gabah isi, jumlah gabah hampa, jumlah gabah total, bobot 100 butir, bobot per rumpun, dan kerapatan malai. Data dianalisis menggunakan analisis ragam (Tabel 1), apabila berbeda nyata dilanjutkan dengan uji beda nyata jujur (BNJ) pada $\alpha 5 \%$. Selanjutnya dilakukan pendugaan parameter genetik yaitu pandugaan ragam genetik, ragam fenotipe, dan ragam lingkungan, heritabilitas arti luas dan korelasi antar karakter. Rumus heritabilitas dan koefisien keragaman genetik (Singh dan Chaudary, 1979) dan penentuan luas atau sempitnya keragaman genetik ditentukan berdasarkan ragam genetik dan standar deviasi ragam genetik (Pinaria et al., 1995) yaitu:

$\mathrm{H}_{\mathrm{bs}}^{2}=\frac{\sigma_{\mathrm{g}}^{2}}{\sigma_{\mathrm{p}}^{2}} \mathrm{KKG}=\sqrt{\frac{\sigma 2 \mathrm{~g}}{X}} \times 100 \% \sigma \sigma_{\mathrm{g}}^{2}=\sqrt{\frac{2}{\mathrm{r}^{2}}}\left[\frac{\mathrm{M}_{2}^{2}}{\mathrm{db}_{\mathrm{g}}+2}+\frac{\mathrm{M}_{1}^{2}}{\mathrm{db}_{\mathrm{e}}+2}\right]$

$\mathrm{H}^{2}{ }_{\mathrm{bs}}=$ heritabilitas arti luas, $\mathrm{KKG}=$ koefisien keragaman genetik, $\sigma \sigma_{\mathrm{g}}^{2}=$ standar deviasi ragam genetik, dimana:

$\sigma_{\mathrm{g}}^{2}>2 \sigma \sigma_{\mathrm{g}}^{2}=$ keragaman genetik luas

$\sigma_{\mathrm{g}}^{2}<2 \sigma \sigma_{\mathrm{g}}^{2}=$ keragaman genetik sempit

Pengelompokan nilai heritabilitas arti luas menurut Stanfield (1983): $0.50<\mathrm{H}_{\text {bs }}^{2}<1.00$ : tinggi; $0.20<\mathrm{H}_{\text {bs }}^{2}<0.50$ : sedang; $\mathrm{H}_{\text {bs }}^{2}<0.20$ : rendah. 
Tabel 1. Analisis ragam satu lokasi satu musim

\begin{tabular}{lccc}
\hline $\begin{array}{l}\text { Sumber } \\
\text { keragaman }\end{array}$ & $\begin{array}{c}\text { Derajat } \\
\text { bebas }\end{array}$ & $\begin{array}{c}\text { Kuadrat } \\
\text { tengah }\end{array}$ & $\begin{array}{c}\text { Nilai } \\
\text { harapan }\end{array}$ \\
\hline Ulangan & $(\mathrm{r}-1)$ & & \\
Genotipe & $(\mathrm{g}-1)$ & $\mathrm{M} 2$ & $\sigma_{\mathrm{e}}^{2}+\mathrm{r}\left(\sigma_{\mathrm{g}}^{2}\right)$ \\
galat & $(\mathrm{r}-1)-(\mathrm{g}-1)$ & $\mathrm{M} 1$ & $\sigma_{\mathrm{e}}^{2}$ \\
\hline
\end{tabular}

Keterangan: $\mathrm{r}=$ ulangan; $\mathrm{g}=$ genotipe; $\sigma_{\mathrm{e}}^{2}=$ ragam lingkungan; $\sigma_{\mathrm{g}}^{2}=$ ragam genotipe

\section{HASIL DAN PEMBAHASAN}

Berdasarkan analisis ragam 48 galur DH0 (generasi pertama) asal kultur antera dan tiga varietas pembanding diketahui bahwa genotipe berbeda sangat nyata pada semua karakter yang diamati (Tabel 2). Hal ini menunjukkan bahwa galur DH0 asal kultur antera memiliki keragaman pada semua karakter pengamatan. Menurut Dewi dan Purwoko (2012), melalui kultur antera hasil rekombinasi dari persilangan difiksasi sebagai galur-galur dihaploid yang homozigot penuh. Bagati et al. (2016) mengemukakan bahwa keragaman genetik tanaman sangat dibutuhkan pada pengembangan karakter padi seperti hasil.

\section{Hasil dan Komponen Hasil}

Galur-galur dihaploid yang baik memiliki karakter agronomi hampir sama atau lebih baik dibandingkan varietas pembanding (Akhmadi et al., 2017). Pada karakter tinggi tanaman, IRRI (2002) mengklasifikasikan tinggi padi sawah menjadi tinggi $(>130 \mathrm{~cm})$, sedang $(110-130 \mathrm{~cm})$, dan pendek $(<110 \mathrm{~cm})$. Berdasarkan pengelompokan tersebut sebanyak 12 galur masuk kategori tinggi, enam galur masuk kategori sedang, dan 30 galur masuk kategori pendek (Tabel $3)$.
Pada karakter jumlah anakan vegetatif, DR9-11-1-1 merupakan galur yang memiliki jumlah anakan tertinggi (34.0) dan tidak berbeda nyata dengan enam galur lainnya (Tabel 3). Menurut Kartina et al. (2017) semakin banyak jumlah anakan, semakin besar peluang terbentuknya anakan produktif. DR9-11-1-1 merupakan galur yang memiliki jumlah anakan banyak, diikuti oleh jumlah anakan produktif yang banyak (27.0). Berdasarkan klasifikasi IRRI (2002) sebanyak 26 galur memiliki jumlah anakan produktif sedang, 20 galur memiliki jumlah anakan produktif tinggi, dan dua galur memiliki jumlah anakan produktif sangat tinggi (Tabel 3).

Panjang malai galur dalam penelitian ini beragam, berkisar antara 19.2-32.6 cm (Tabel 3). Secara umum malai yang lebih panjang berasosiasi dengan jumlah gabah per malai, dan membuat produktivitasnya semakin tinggi (Widyastuti et al., 2015). Terdapat 13 galur dengan panjang malai lebih panjang dibandingkan Ciherang, sedangkan 27 galur memiliki panjang malai lebih panjang dibandingkan Inpari 18.

Umur berbunga 48 galur DH0 asal kultur antera dan tiga varietas pembanding dalam penelitian ini berkisar antara 72-101 hari (Tabel 3). Sebanyak lima galur memiliki umur berbunga setara Inpari 18. Terdapat 24 galur dengan umur berbunga setara atau lebih cepat dibandingkan Inpago 10 , sedangkan 42 galur mempunyai umur berbunga yang setara atau lebih cepat dibanding Ciherang. Dari 36 galur dengan tetua Inpari 18, hanya terdapat empat galur yang memiliki umur setara dengan Inpari 18.

Tantangan pemuliaan tanaman padi salah satunya adalah memperpendek umur tanaman tanpa mengorbankan hasil (Lang et al., 2014). Berdasarkan uji BNJ diketahui terdapat lima galur dengan umur panen setara Inpari 18 (Tabel 3). Terdapat satu galur dengan umur panen tercepat berbeda dengan varietas pembanding dan 47 galur lainnya.

Gabah merupakan salah satu komponen hasil penting pada tanaman padi karena menentukan produksi. Tujuh

Tabel 2. Analisis ragam galur galur dihaploid DH0 asal kultur antera

\begin{tabular}{lrc}
\hline Karakter agronomi & \multicolumn{1}{c}{ Galur } & Koefisien keragaman (\%) \\
\hline Tinggi tanaman generatif & $1,263.2212^{* *}$ & 3.56 \\
Jumlah anakan & $88.3383^{* *}$ & 15.91 \\
Jumlah anakan produktif & $44.0732^{* *}$ & 16.38 \\
Umur berbunga & $109.6024^{* *}$ & 1.94 \\
Panjang malai & $26.6299^{* *}$ & 4.85 \\
Jumlah gabah isi per malai & $7,404.2654^{* *}$ & 12.51 \\
Jumlah gabah hampa per malai & $4,392.9098^{* *}$ & 38.34 \\
Jumlah gabah per malai & $15,029.8169^{* *}$ & 10.61 \\
Bobot 100 butir & $0.1767^{* *}$ & 4.88 \\
Bobot gabah kering per rumpun & $569.4810^{* *}$ & 19.29 \\
Kerapatan malai & $17.7849^{* *}$ & 9.06 \\
Umur panen & $137.5788^{* *}$ & 1.55 \\
\hline
\end{tabular}

Keterangan: $* *=$ berpengaruh nyata pada $\alpha 1 \% ; *=$ berpengaruh nyata pada $\alpha 5 \%$ 
Syafii et al. / J. Agron. Indonesia 46(1):9-16

Tabel 3. Karakter agronomi galur DH0 asal kultur antera dan varietas pembanding

\begin{tabular}{|c|c|c|c|c|c|c|c|c|c|c|c|c|}
\hline Galur & TG & JA & JAP & PM & UB & UP & GI & $\mathrm{GH}$ & GT & B100 & $\mathrm{BR}$ & $\mathrm{KM}$ \\
\hline DR7-1-1-1 & $134.3 \mathrm{de}$ & $24.7 \mathrm{e}-\mathrm{j}$ & $20.7 \mathrm{c}-\mathrm{k}$ & $32.6 \mathrm{ab}$ & $88.0 \mathrm{cde}$ & $113.7 \mathrm{~d}-\mathrm{h}$ & $210.9 \mathrm{f}-\mathrm{k}$ & $35.9 f-p$ & $246.8 \mathrm{k}-\mathrm{p}$ & $2.84 \mathrm{bc}$ & $70.3 b-i$ & $7.6 p-t$ \\
\hline DR7-1-1-2 & $139.0 \mathrm{~cd}$ & 20.7h-o & $17.7 \mathrm{~h}-\mathrm{q}$ & $31.7 \mathrm{bc}$ & $6.3 \mathrm{e}-\mathrm{h}$ & $112.3 \mathrm{ghi}$ & $202.6 \mathrm{~g}-\mathrm{m}$ & $27.8 \mathrm{~h}-\mathrm{s}$ & $230.3 n-t$ & $.71 \mathrm{~b}-\mathrm{h}$ & $55.6 \mathrm{~h}-\mathrm{q}$ & $7.3 \mathrm{q}-\mathrm{t}$ \\
\hline DR7-3-4-1 & $151.3 \mathrm{a}$ & $16.7 \mathrm{no}$ & $15.0 \mathrm{~m}-\mathrm{r}$ & $30.7 \mathrm{~b}-\mathrm{e}$ & $81.01 \mathrm{mn}$ & $106.0 \mathrm{~m}-\mathrm{p}$ & $291.7 \mathrm{a}$ & $32.8 \mathrm{f}-\mathrm{r}$ & $324.5 \mathrm{c}-\mathrm{f}$ & $2.340-u$ & 65.1d-1 & 10.6e-i \\
\hline DR7-7-6-1 & $118.3 \mathrm{jk}$ & $19.7 \mathrm{i}-\mathrm{o}$ & $16.0 \mathrm{j}-\mathrm{r}$ & $30.7 \mathrm{~b}-\mathrm{e}$ & $81.01 \mathrm{mn}$ & $106.0 \mathrm{~m}-\mathrm{p}$ & $229.1 \mathrm{c}-\mathrm{h}$ & $149.3 b$ & $378.4 \mathrm{~b}$ & $2.56 \mathrm{f}-\mathrm{n}$ & $57.9 \mathrm{f}-\mathrm{q}$ & $12.4 \mathrm{bc}$ \\
\hline DR7-20-1-1 & $153.0 \mathrm{a}$ & $23.3 \mathrm{~g}-1$ & $20.0 \mathrm{~d}-\mathrm{m}$ & $27.3 \mathrm{i}-\mathrm{o}$ & $101.0 \mathrm{a}$ & $128.0 \mathrm{a}$ & $224.7 \mathrm{~d}-\mathrm{h}$ & $81.8 \mathrm{~cd}$ & $306.4 d-g$ & $2.29 \mathrm{r}-\mathrm{v}$ & $66.3 \mathrm{~d}-\mathrm{k}$ & $11.2 \mathrm{c}-\mathrm{g}$ \\
\hline DR7-21-1-1 & $97.7 \mathrm{p}-\mathrm{u}$ & $23.7 \mathrm{f}-1$ & $17.7 \mathrm{~h}-\mathrm{q}$ & $27.6 \mathrm{~h}-\mathrm{o}$ & $90.7 b$ & $116.0 \mathrm{bcd}$ & $215.4 \mathrm{f}-\mathrm{j}$ & $34.2 \mathrm{f}-\mathrm{q}$ & $249.7 \mathrm{k}-\mathrm{p}$ & $2.49 \mathrm{i}-\mathrm{r}$ & $45.0 \mathrm{n}-\mathrm{r}$ & $9.1 \mathrm{j}-\mathrm{o}$ \\
\hline DR7-21-1-2 & 95.7r-u & $22.0 \mathrm{~g}-\mathrm{n}$ & $17.7 \mathrm{~h}-\mathrm{q}$ & $26.2 \mathrm{n}-\mathrm{s}$ & $89.7 \mathrm{bcd}$ & $114.7 \mathrm{c}-\mathrm{g}$ & 188.0i-p & 25.6i-s & $213.6 \mathrm{p}-\mathrm{v}$ & $2.44 \mathrm{k}-\mathrm{s}$ & 47.11-r & $8.1 \mathrm{~m}-\mathrm{r}$ \\
\hline DR7-26-3-1 & $100.7 \mathrm{n}-\mathrm{s}$ & $19.0 \mathrm{j}-\mathrm{o}$ & $16.7 \mathrm{i}-\mathrm{r}$ & $26.6 \mathrm{k}-\mathrm{r}$ & $78.3 \mathrm{~m}-\mathrm{p}$ & $103.7 \mathrm{pqr}$ & $267.2 \mathrm{abc}$ & $36.8 \mathrm{f}-\mathrm{p}$ & $304.0 \mathrm{e}-\mathrm{i}$ & $2.50 \mathrm{i}-\mathrm{q}$ & $64.7 \mathrm{~d}-1$ & $11.4 \mathrm{c}-\mathrm{g}$ \\
\hline DR7-31-2-1 & $119.3 \mathrm{ij}$ & $23.0 \mathrm{~g}-\mathrm{m}$ & $19.7 e-n$ & $27.1 \mathrm{k}-\mathrm{q}$ & 83.7ijk & $109.3 \mathrm{jkl}$ & 125.6tuv & $19.1 \mathrm{k}-\mathrm{s}$ & $144.7 \mathrm{z}-\mathrm{C}$ & $2.78 \mathrm{~b}-\mathrm{e}$ & $53.2 \mathrm{i}-\mathrm{q}$ & $5.4 \mathrm{v}$ \\
\hline DR7-31-1-1 & $127.3 \mathrm{fgh}$ & $15.7 \mathrm{o}$ & 14.3pqr & $30.1 \mathrm{c}-\mathrm{g}$ & $76.7 \mathrm{qr}$ & 101.3rst & $288.1 \mathrm{ab}$ & 71.6cde & $359.7 b c$ & $2.74 \mathrm{~b}-\mathrm{g}$ & $67.7 \mathrm{~d}-\mathrm{k}$ & $11.9 \mathrm{cde}$ \\
\hline DR7-35-1-1 & $103.3 \mathrm{~m}-\mathrm{q}$ & $26.7 \mathrm{c}-\mathrm{h}$ & $23.7 \mathrm{a}-\mathrm{g}$ & $28.6 \mathrm{e}-1$ & $79.3 \mathrm{~m}-\mathrm{p}$ & $105.7 \mathrm{~m}-\mathrm{p}$ & $174.8 \mathrm{k}-\mathrm{r}$ & $45.6 \mathrm{e}-1$ & $220.3 \mathrm{o}-\mathrm{u}$ & $2.63 \mathrm{~d}-\mathrm{k}$ & $56.8 \mathrm{~g}-\mathrm{q}$ & $7.7 \mathrm{o}-\mathrm{t}$ \\
\hline DR7-37-1-1 & 124.7hij & $23.3 \mathrm{~g}-1$ & $18.7 \mathrm{~g}-\mathrm{p}$ & $27.3 \mathrm{j}-\mathrm{p}$ & $84.0 \mathrm{~g}-\mathrm{j}$ & $109.3 \mathrm{jkl}$ & $161.1 \mathrm{n}-\mathrm{t}$ & $18.31-\mathrm{s}$ & $179.5 \mathrm{u}-\mathrm{A}$ & $2.49 \mathrm{i}-\mathrm{r}$ & $55.1 \mathrm{~h}-\mathrm{q}$ & 6.6tuv \\
\hline DR7-43-1-5 & $101.3 \mathrm{~m}-\mathrm{r}$ & $18.7 \mathrm{j}-\mathrm{o}$ & $16.7 \mathrm{i}-\mathrm{r}$ & $28.4 \mathrm{f}-\mathrm{m}$ & $76.7 \mathrm{qr}$ & $102.7 \mathrm{qrs}$ & 257.7a-e & $88.1 \mathrm{c}$ & $345.8 \mathrm{~b}-\mathrm{e}$ & $2.39 \mathrm{~m}-\mathrm{u}$ & $55.1 \mathrm{~h}-\mathrm{q}$ & $12.2 \mathrm{~cd}$ \\
\hline DR7-44-1-2 & $102.3 \mathrm{~m}-\mathrm{q}$ & $16.7 \mathrm{no}$ & $14.7 \mathrm{n}-\mathrm{r}$ & $28.7 \mathrm{e}-\mathrm{k}$ & $75.3 \mathrm{rs}$ & $100.7 \mathrm{stu}$ & $267.7 \mathrm{abc}$ & $44.0 \mathrm{f}-\mathrm{m}$ & $311.7 \mathrm{~d}-\mathrm{g}$ & $2.411-\mathrm{u}$ & $60.8 f-p$ & $10.9 \mathrm{~d}-\mathrm{h}$ \\
\hline DR7-48-2-1 & $93.7 \mathrm{t}-\mathrm{w}$ & $31.3 \mathrm{bcd}$ & $19.7 \mathrm{e}-\mathrm{n}$ & $26.6 \mathrm{k}-\mathrm{r}$ & $79.0 \mathrm{~m}-\mathrm{p}$ & 104.0o-r & $199.3 \mathrm{~g}-\mathrm{n}$ & $29.2 \mathrm{~g}-\mathrm{s}$ & $228.6 n-t$ & $2.45 \mathrm{k}-\mathrm{s}$ & $52.1 \mathrm{i}-\mathrm{q}$ & 8.61-q \\
\hline DR7-67-2-1 & $76.7 \mathrm{z}$ & $30.3 b-e$ & $24.3 a-f$ & $20.0 \mathrm{wx}$ & $90.3 b c$ & $117.7 \mathrm{~b}$ & $97.1 \mathrm{v}$ & 7.3qrs & $104.4 \mathrm{C}$ & $2.89 \mathrm{~b}$ & 43.2pqr & $5.2 \mathrm{v}$ \\
\hline DR7-69-1-1 & $83.3 y$ & $22.7 \mathrm{~g}-\mathrm{n}$ & $21.0 \mathrm{c}-\mathrm{j}$ & $26.3 \mathrm{~m}-\mathrm{s}$ & $86.3 \mathrm{e}-\mathrm{h}$ & $112.0 \mathrm{~g}-\mathrm{j}$ & 187.6i-p & $87.7 \mathrm{c}$ & $275.2 \mathrm{~h}-$ & $2.91 \mathrm{~b}$ & $63.9 \mathrm{~d}-\mathrm{m}$ & $10.4 \mathrm{f}-\mathrm{j}$ \\
\hline DR7-69-1-3 & $85.7 x y$ & $22.7 \mathrm{~g}-\mathrm{n}$ & $19.3 \mathrm{f}-\mathrm{o}$ & $25.90-\mathrm{t}$ & 86.7efg & 112.3ghi & $179.7 \mathrm{j}-\mathrm{q}$ & $93.3 \mathrm{c}$ & $273.0 \mathrm{~h}-$ & $2.79 \mathrm{bcd}$ & $62.4 \mathrm{e}-\mathrm{o}$ & $10.5 \mathrm{f}-\mathrm{i}$ \\
\hline DR7-69-1-4 & $84.7 y$ & $24.3 \mathrm{e}-\mathrm{k}$ & $22.7 b-h$ & $26.1 \mathrm{n}-\mathrm{s}$ & $87.7 \mathrm{def}$ & $113.0 \mathrm{e}-\mathrm{h}$ & $163.5 \mathrm{~m}-\mathrm{t}$ & $79.7 \mathrm{~cd}$ & 243.11-r & $2.91 \mathrm{~b}$ & $62.6 \mathrm{e}-\mathrm{o}$ & $9.3 \mathrm{i}-\mathrm{n}$ \\
\hline DR7-75-1-1 & $100.0 \mathrm{o}-\mathrm{t}$ & 16.7 no & $15.31-\mathrm{r}$ & $28.2 \mathrm{~g}-\mathrm{n}$ & $81.01 \mathrm{mn}$ & $107.7 \mathrm{klm}$ & $291.2 \mathrm{a}$ & $145.3 b$ & $436.6 \mathrm{a}$ & $2.30 \mathrm{q}-\mathrm{u}$ & $63.3 \mathrm{~d}-\mathrm{n}$ & $15.5 \mathrm{a}$ \\
\hline DR7-95-1-1 & $105.3 \mathrm{mno}$ & $18.3 \mathrm{k}-\mathrm{o}$ & $12.0 \mathrm{qr}$ & $29.6 \mathrm{c}-\mathrm{h}$ & $90.7 \mathrm{~b}$ & $117.3 \mathrm{bc}$ & $192.7 \mathrm{~h}-\mathrm{o}$ & 7.0qrs & $199.7 \mathrm{~s}-\mathrm{x}$ & 2.24 tuv & $39.7 \mathrm{qr}$ & $6.8 \mathrm{stu}$ \\
\hline DR7-58-3-1 & $147.7 \mathrm{ab}$ & $25.7 \mathrm{c}-\mathrm{i}$ & $20.3 \mathrm{~d}-1$ & $26.6 \mathrm{k}-\mathrm{r}$ & $90.0 \mathrm{bcd}$ & $116.3 \mathrm{bcd}$ & $223.8 \mathrm{~d}-\mathrm{i}$ & $12.8 \mathrm{n}-\mathrm{s}$ & $236.6 \mathrm{~m}-\mathrm{s}$ & $2.40 \mathrm{~m}-\mathrm{u}$ & $69.3 b-j$ & $8.9 \mathrm{k}-\mathrm{p}$ \\
\hline DR12-8-1-2 & $98.3 p-u$ & $25.7 \mathrm{c}-\mathrm{i}$ & $18.3 \mathrm{~h}-\mathrm{p}$ & $26.6 \mathrm{k}-\mathrm{r}$ & $87.7 \mathrm{def}$ & $113.7 \mathrm{~d}-\mathrm{h}$ & $127.7 \mathrm{~s}-\mathrm{v}$ & $23.8 \mathrm{j}-\mathrm{s}$ & $151.4 y-B$ & $3.38 \mathrm{a}$ & $45.3 \mathrm{~m}-\mathrm{r}$ & $5.7 \mathrm{uv}$ \\
\hline DR8-13-1-3 & $101.3 \mathrm{~m}-\mathrm{r}$ & $19.0 \mathrm{j}-\mathrm{o}$ & $15.7 \mathrm{k}-\mathrm{r}$ & $25.2 \mathrm{p}-\mathrm{u}$ & $73.0 \mathrm{st}$ & $97.7 \mathrm{v}$ & 167.91-s & $33.0 \mathrm{f}-\mathrm{r}$ & $200.9 \mathrm{~s}-\mathrm{x}$ & $2.39 \mathrm{~m}-\mathrm{u}$ & $41.8 \mathrm{qr}$ & 8.0n-s \\
\hline DR8-20-1-1 & $112.0 \mathrm{kl}$ & $23.0 \mathrm{~g}-\mathrm{m}$ & $22.7 \mathrm{~b}-\mathrm{h}$ & $23.9 \mathrm{tu}$ & $80.01-\mathrm{o}$ & $104.7 n-q$ & $250.0 b-f$ & $31.0 \mathrm{f}-\mathrm{s}$ & $281.0 \mathrm{~g}-1$ & $2.66 \mathrm{c}-\mathrm{j}$ & $88.0 \mathrm{ab}$ & $11.7 \mathrm{c}-\mathrm{f}$ \\
\hline DR12-20-1-2 & $94.3 \mathrm{~s}-\mathrm{v}$ & $25.7 \mathrm{c}-\mathrm{i}$ & $19.7 \mathrm{e}-\mathrm{n}$ & $27.5 \mathrm{~h}-\mathrm{o}$ & 86.7 efg & $113.0 \mathrm{e}-\mathrm{h}$ & 185.6i-q & $18.51-\mathrm{s}$ & $204.0 \mathrm{q}-\mathrm{w}$ & $2.57 \mathrm{i}-\mathrm{q}$ & $50.5 \mathrm{k}-\mathrm{r}$ & $7.4 q-\mathrm{t}$ \\
\hline DR8-23-2-3 & $107.01 \mathrm{mn}$ & $26.3 \mathrm{c}-\mathrm{h}$ & $25.7 \mathrm{abc}$ & $24.5 \mathrm{r}-\mathrm{u}$ & $74.0 \mathrm{st}$ & 101.7rst & $145.2 \mathrm{q}-\mathrm{u}$ & $15.3 \mathrm{n}-\mathrm{s}$ & $160.5 x-B$ & $2.61 \mathrm{~d}-1$ & $69.0 \mathrm{c}-\mathrm{k}$ & 6.5 tuv \\
\hline DR8-31-1-1 & $87.3 \mathrm{wxy}$ & $30.3 b-e$ & $22.7 \mathrm{~b}-\mathrm{h}$ & $19.2 \mathrm{x}$ & $73.7 \mathrm{st}$ & $90.7 \mathrm{w}$ & $111.3 \mathrm{uv}$ & $10.0 \mathrm{p}-\mathrm{s}$ & $121.3 \mathrm{BC}$ & $2.51 \mathrm{i}-\mathrm{p}$ & $44.1 \mathrm{o}-\mathrm{r}$ & 6.3 tuv \\
\hline DR8-32-2-1 & $103.0 \mathrm{~m}-\mathrm{q}$ & $15.0 \mathrm{o}$ & $13.0 \mathrm{qr}$ & $23.1 \mathrm{uv}$ & $85.3 \mathrm{e}-\mathrm{h}$ & $112.7 \mathrm{fgh}$ & 169.91-r & $18.9 \mathrm{k}-\mathrm{s}$ & $188.8 \mathrm{t}-\mathrm{y}$ & & 40.7 & $8.2 \mathrm{~m}-\mathrm{r}$ \\
\hline DR11-36-1-1 & $104.0 \mathrm{~m}-\mathrm{p}$ & $25.3 \mathrm{~d}-\mathrm{i}$ & $22.3 \mathrm{~b}-\mathrm{h}$ & 26.51-r & 86.7 efg & $113.0 \mathrm{e}-\mathrm{h}$ & $178.1 \mathrm{j}-\mathrm{q}$ & $38.4 \mathrm{f}-\mathrm{n}$ & & & & $8.2 \mathrm{~m}-\mathrm{r}$ \\
\hline DR8-43-3-1 & $150.0 \mathrm{a}$ & $18.01-\mathrm{o}$ & $15.0 \mathrm{~m}-\mathrm{r}$ & & & $114.0 \mathrm{~d}-\mathrm{g}$ & & & & & & 9.6h-1 \\
\hline DR12-52-2-1 & $137.7 \mathrm{cde}$ & $18.3 \mathrm{k}-\mathrm{o}$ & $18.3 \mathrm{~h}-\mathrm{p}$ & $25.90-t$ & $82.3 \mathrm{jkl}$ & & & $56.6 \mathrm{~d}-\mathrm{g}$ & & & & $12.4 \mathrm{bc}$ \\
\hline DR12-81-1-1 & 125.3ghi & $19.7 \mathrm{i}-\mathrm{o}$ & $17.0 \mathrm{i}-\mathrm{r}$ & $27.8 \mathrm{~h}-\mathrm{o}$ & $88.3 \mathrm{~b}-\mathrm{e}$ & $114.3 \mathrm{~d}-\mathrm{g}$ & $205.7 \mathrm{~g}-1$ & $51.8 \mathrm{e}-\mathrm{i}$ & $257.5 \mathrm{j}-\mathrm{o}$ & $2.26 \mathrm{~s}-\mathrm{v}$ & $50.9 \mathrm{j}-\mathrm{r}$ & $9.2 \mathrm{i}-\mathrm{n}$ \\
\hline DR8-18-1-1 & $92.3 \mathrm{uvw}$ & $17.0 \mathrm{mno}$ & $16.0 \mathrm{j}-\mathrm{r}$ & $24.8 \mathrm{r}-\mathrm{u}$ & $87.7 \mathrm{def}$ & 115.7b-e & $162.8 \mathrm{~m}-\mathrm{t}$ & $22.6 \mathrm{j}-\mathrm{s}$ & & $2.57 \mathrm{e}-\mathrm{m}$ & $40.1 \mathrm{qr}$ & $7.5 \mathrm{q}-\mathrm{t}$ \\
\hline DR8-122-1-1 & $142.3 \mathrm{bc}$ & $29.7 b-f$ & $23.7 \mathrm{a}-\mathrm{g}$ & $30.5 b-f$ & $88.0 \mathrm{cde}$ & $115.3 \mathrm{bf}$ & $148.0 \mathrm{p}-\mathrm{u}$ & $201.9 \mathrm{a}$ & $349.9 \mathrm{bcd}$ & & $57.5 \mathrm{f}-\mathrm{q}$ & $11.5 \mathrm{c}-\mathrm{g}$ \\
\hline DR9-4-1-1 & $107.71 \mathrm{~m}$ & $30.0 \mathrm{~b}-\mathrm{e}$ & $22.7 \mathrm{~b}-\mathrm{h}$ & $25.80-\mathrm{t}$ & $78.0 \mathrm{pq}$ & 106.71-o & $263.5 \mathrm{a}-\mathrm{d}$ & 45.0e-m & $308.5 \mathrm{~d}-\mathrm{g}$ & & $94.0 \mathrm{a}$ & 11.9cde \\
\hline DR9-11-1-1 & $97.7 p-u$ & $34.0 \mathrm{~b}$ & $27.0 \mathrm{ab}$ & $21.7 \mathrm{vw}$ & $74.3 \mathrm{rs}$ & 99.0tuv & & $34.2 \mathrm{f}-\mathrm{q}$ & & & & $12.2 \mathrm{bcc}$ \\
\hline DR9-11-1-2 & $97.0 \mathrm{q}-\mathrm{u}$ & $31.7 \mathrm{bc}$ & $25.0 \mathrm{a}-\mathrm{d}$ & $21.6 \mathrm{vw}$ & $74.0 \mathrm{st}$ & 99.3tuv & $237.6 \mathrm{c}-\mathrm{g}$ & $54.4 \mathrm{~d}-\mathrm{h}$ & 292.0f-j & & & $13.6 \mathrm{~b}$ \\
\hline DR9-58-1-1 & $131.7 \mathrm{efg}$ & $24.7 e-j$ & $23.7 \mathrm{a}-\mathrm{g}$ & $30.2 \mathrm{c}-\mathrm{g}$ & 80.71-o & $107.0 \mathrm{k}-\mathrm{n}$ & $199.3 \mathrm{~g}-\mathrm{n}$ & $30.6 \mathrm{f}-\mathrm{s}$ & $229.9 n-t$ & $2.37 n-u$ & $69.2 b-j$ & 7.6p-t \\
\hline DR9-69-2-2 & $143.0 \mathrm{bc}$ & $26.0 \mathrm{c}-\mathrm{h}$ & $21.7 \mathrm{c}-\mathrm{i}$ & $31.4 \mathrm{bcd}$ & 85.0ghi & 111.0hij & $165.71-\mathrm{t}$ & & $169.8 \mathrm{w}-\mathrm{A}$ & $2.66 c-i$ & $69.5 b-j$ & $5.4 \mathrm{uv}$ \\
\hline DR9-67-1-1 & $132.7 \mathrm{def}$ & $22.3 g-n$ & $14.7 n-r$ & $27.2 \mathrm{j}-\mathrm{q}$ & $84.7 \mathrm{~g}-\mathrm{j}$ & $109.7 \mathrm{ijk}$ & 259.1a-e & $39.7 \mathrm{f}-\mathrm{n}$ & $298.8 f-j$ & $2.54 \mathrm{~g}-\mathrm{o}$ & $62.4 \mathrm{e}-\mathrm{o}$ & $11.0 \mathrm{c}-\mathrm{g}$ \\
\hline DR10-14-1-1 & $101.3 \mathrm{~m}-\mathrm{r}$ & $22.7 \mathrm{~g}-\mathrm{n}$ & $21.0 \mathrm{c}-\mathrm{j}$ & $25.1 \mathrm{q}-\mathrm{u}$ & $74.0 \mathrm{st}$ & $99.7 \mathrm{stu}$ & $238.0 \mathrm{c}-\mathrm{g}$ & $46.2 \mathrm{e}-\mathrm{k}$ & $284.2 \mathrm{f}-1$ & $2.23 \mathrm{uv}$ & $66.1 \mathrm{~d}-\mathrm{k}$ & $11.3 \mathrm{c}-\mathrm{g}$ \\
\hline DR10-26-1-1 & $88.7 v-y$ & $25.7 \mathrm{c}-\mathrm{i}$ & $22.3 b-h$ & $25.1 \mathrm{q}-\mathrm{u}$ & 83.7ijk & 109.7ijk & $135.0 \mathrm{r}-\mathrm{v}$ & $6.7 \mathrm{rs}$ & $141.67 \mathrm{ABC}$ & $2.32 p-u$ & $39.5 \mathrm{qr}$ & 5.6uv \\
\hline DR10-27-1-1 & $132.0 \mathrm{ef}$ & $27.3 \mathrm{c}-\mathrm{g}$ & $24.7 \mathrm{a}-\mathrm{e}$ & $29.2 \mathrm{e}-\mathrm{j}$ & $87.7 \mathrm{def}$ & $114.0 \mathrm{~d}-\mathrm{g}$ & 185.9i-p & $58.0 \mathrm{def}$ & $243.9 \mathrm{k}-\mathrm{r}$ & $2.85 \mathrm{bc}$ & $80.9 \mathrm{a}-\mathrm{e}$ & 8.41-r \\
\hline DR10-27-3-1 & 92.3uvw & $22.7 \mathrm{~g}-\mathrm{n}$ & $20.7 \mathrm{c}-\mathrm{k}$ & $24.8 \mathrm{r}-\mathrm{u}$ & $88.3 \mathrm{~b}-\mathrm{e}$ & $114.7 \mathrm{c}-\mathrm{g}$ & $147.7 \mathrm{p}-\mathrm{u}$ & $29.9 \mathrm{~g}-\mathrm{s}$ & $177.6 \mathrm{v}-\mathrm{A}$ & $2.53 \mathrm{~h}-\mathrm{o}$ & $44.5 \mathrm{o}-\mathrm{r}$ & $7.2 \mathrm{rst}$ \\
\hline DR10-42-1-1 & 125.3ghi & 16.7 no & $13.7 \mathrm{pqr}$ & $28.2 \mathrm{~g}-\mathrm{n}$ & 86.7efg & $114.0 \mathrm{~d}-\mathrm{g}$ & 260.3a-e & $25.1 \mathrm{i}-\mathrm{s}$ & $285.5 \mathrm{f}-\mathrm{k}$ & $2.46 \mathrm{i}-\mathrm{s}$ & $62.7 \mathrm{e}-\mathrm{o}$ & $10.1 \mathrm{~g}-\mathrm{k}$ \\
\hline DR10-47-3-1 & $93.7 \mathrm{t}-\mathrm{w}$ & $17.0 \mathrm{mno}$ & $15.7 \mathrm{k}-\mathrm{r}$ & $25.80-\mathrm{t}$ & $76.7 \mathrm{qr}$ & 101.3rst & $220.6 \mathrm{e}-\mathrm{i}$ & $25.2 \mathrm{i}-\mathrm{s}$ & $245.8 \mathrm{k}-\mathrm{q}$ & $2.32 p-u$ & $52.4 \mathrm{i}-\mathrm{q}$ & $9.5 \mathrm{i}-\mathrm{m}$ \\
\hline DR10-26-1-3 & $94.3 \mathrm{~s}-\mathrm{v}$ & $27.0 \mathrm{c}-\mathrm{g}$ & $20.7 \mathrm{c}-\mathrm{k}$ & $25.80-\mathrm{t}$ & $82.0 \mathrm{kl}$ & $108.0 \mathrm{klm}$ & 126.6tuv & $17.7 \mathrm{~m}-\mathrm{s}$ & $144.1 z-C$ & $2.30 \mathrm{q}-\mathrm{u}$ & $32.4 \mathrm{r}$ & $5.6 \mathrm{uv}$ \\
\hline
\end{tabular}


Syafii et al. / J. Agron. Indonesia 46(1):9-16

Tabel 3. Karakter agronomi galur DH0 asal kultur antera dan varietas pembanding (lanjutan)

\begin{tabular}{lccccccccccccc}
\hline Galur & TG & JA & JAP & PM & UB & UP & GI & GH & GT & B100 & BR & KM \\
Ciherang & $106.7 \mathrm{lmn}$ & $43.0 \mathrm{a}$ & $28.3 \mathrm{a}$ & $26.4 \mathrm{~m}-\mathrm{s}$ & $86.3 \mathrm{e}-\mathrm{h}$ & $114.0 \mathrm{~d}-\mathrm{g}$ & $157.1 \mathrm{o}-\mathrm{t}$ & $10.5 \mathrm{o}-\mathrm{s}$ & $167.6 \mathrm{w}-\mathrm{A}$ & $2.46 \mathrm{j}-\mathrm{s}$ & $72.6 \mathrm{~b}-\mathrm{h}$ & $6.4 \mathrm{tuv}$ \\
Inpari 18 & $92.0 \mathrm{u}-\mathrm{x}$ & $23.0 \mathrm{~g}-\mathrm{m}$ & $20.7 \mathrm{c}-\mathrm{k}$ & $24.3 \mathrm{stu}$ & $71.7 \mathrm{t}$ & $98.0 \mathrm{uv}$ & $164.5 \mathrm{~m}-\mathrm{t}$ & $37.9 \mathrm{f}-\mathrm{o}$ & $202.3 \mathrm{r}-\mathrm{x}$ & $2.90 \mathrm{~b}$ & $54.8 \mathrm{~h}-\mathrm{q}$ & $8.31-\mathrm{r}$ \\
Inpago 10 & $120.7 \mathrm{ij}$ & $26.0 \mathrm{c}-\mathrm{h}$ & $21.7 \mathrm{c}-\mathrm{i}$ & $33.8 \mathrm{a}$ & $81.7 \mathrm{klm}$ & $106.71 \mathrm{l}-\mathrm{o}$ & $222.0 \mathrm{e}-\mathrm{i}$ & $48.3 \mathrm{e}-\mathrm{j}$ & $270.3 \mathrm{~h}-\mathrm{n}$ & $2.54 \mathrm{~g}-\mathrm{o}$ & $81.6 \mathrm{a}-\mathrm{d}$ & $8.2 \mathrm{~m}-\mathrm{r}$ \\
\hline
\end{tabular}

Keterangan: $\mathrm{TG}=$ tinggi generatif; $\mathrm{JA}=$ jumlah anakan; JAP $=$ jumlah anakan produktif; $\mathrm{PM}=$ panjang malai; $\mathrm{UB}=$ umur berbunga; $\mathrm{UP}=$ umur panen; $\mathrm{B} 100$ = bobot 100 butir; $\mathrm{BR}=$ bobot gabah kering per rumpun; $\mathrm{PM}=$ panjang malai; $\mathrm{GI}=$ jumlah gabah isi per malai; $\mathrm{GH}=$ jumlah gabah hampa per malai; $\mathrm{GT}=$ jumlah gabah total per malai; $\mathrm{KM}=$ kerapatan malai. Angka dalam satu kolom yang sama yang diikuti huruf sama tidak berbeda nyata pada uji BNJ pada taraf $\alpha 5 \%$

galur yang memiliki jumlah gabah isi per malai nyata lebih banyak dibandingkan 3 varietas pembanding yaitu DR7-34-1 (291.7 bulir), DR7-75-1-1 (291.2 butir), DR7-31-1-1 (288.1 butir), DR7-26-3-1 (267.2 butir), DR7-44-1-2 (267.7 butir), DR12-52-2-1 (264.3 butir), DR9-4-1-1 (263.5 butir). Sebanyak 28 galur mempunyai jumlah gabah hampa per malai setara Ciherang, dan 28 galur setara Inpago 10 (Tabel 3). Jumlah gabah total 48 galur DH0 dalam penelitian ini berkisar antara 104.4-436.6 butir per malai (Tabel 3). Galur dengan jumlah gabah total nyata lebih tinggi dibanding tiga varietas pembanding sebanyak sepuluh galur.

Kerapatan malai merupakan karakter penting dalam mendukung produksi selain jumlah gabah isi, karena kerapatan malai lebih mempengaruhi jumlah gabah per malai dibandingkan panjang malai. Inpago 10 merupakan varietas pembanding dengan malai terpanjang $(33.8 \mathrm{~cm})$, namun hanya memiliki jumlah gabah total 270.3 butir per malai, sedangkan DR9-11-1-2 memiliki panjang malai 21.6 $\mathrm{cm}$ namun jumlah gabah totalnya 292.0 butir per malai. Hal yang sama juga dilaporkan oleh Dewi et al. (2009) pada kegiatan karakterisasi padi dihaploid. Terdapat 19 galur DH0 dengan kerapatan malai lebih rapat dibandingkan tiga varietas pembanding (Tabel 3). Secara keseluruhan, kerapatan malai galur DH0 asal kultur antera ini lebih rapat atau setara dengan varietas pembanding.

Bobot butir padi ditentukan oleh ukuran sekam, aktivitas sink, dan kapasitas source (Kato dan Katsura, 2014). Galur DH0 dalam penelitian ini memiliki bobot gabah 100 butir antara 2.01-3.38 g (Tabel 3). DR12-8-1-2 merupakan galur yang memiliki bobot 100 butir lebih berat dibandingkan tiga varietas pembanding. Hanya empat galur yang memiliki bobot 100 butir lebih ringan dibandingkan dengan tiga varietas pembanding. Menurut Dewi et al. (2009) galur dengan bobot 100 butir tinggi akan cenderung memiliki bobot per rumpun tinggi apabila didukung oleh karakter lain.

Berdasarkan uji BNJ 5\% diketahui bahwa galur DR9-4-1-1 memiliki bobot gabah per rumpun (hasil) nyata lebih berat dibandingkan varietas pembanding Ciherang dan Inpari 18 (Tabel 3). Sebanyak enam galur memiliki bobot per rumpun lebih berat dibandingkan Inpari 18 . Terdapat 20 galur dengan bobot per rumpun setara Inpago 10, 30 galur setara Ciherang, dan 42 galur setara Inpari 18. Dengan demikian hampir sebagian besar galur dihaploid dalam penelitian ini memiliki hasil setara atau lebih berat dibandingkan varietas pembanding.
Berdasarkan bobot per rumpun, terpilih 25 galur terbaik yang memiliki bobot per rumpun diatas $60 \mathrm{~g}$ (data tidak ditampilkan). Hasil persilangan Inpari 18/IR83140B-11-B//Gajah Mungkur menghasilkan jumlah galur terpilih terbanyak yaitu enam dari enam galur, sedangkan persilangan Inpari 22/IR87705-14-11-B-SKI-12//Gajah Mungkur menghasilkan jumlah galur terpilih paling sedikit yaitu tiga dari tujuh galur. Persilangan Inpari 22/IR83140B-11-B//Gajah Mungkur menghasilkan satu galur terpilih dari satu galur yang dikarakterisasi.

\section{Keragaman Genetik Galur DHO}

Penggunaan antera F1 ditujukan untuk memperoleh tanaman setara populasi F2, namun secara langsung homozigot penuh. Hal tersebut terkonfirmasi dari kegiatan ini, keragaman genetik dari 15 karakter menunjukkan keragaman genetik tinggi $\left(\sigma_{\mathrm{g}}^{2}>2 \sigma \sigma_{\mathrm{g}}^{2}\right)$ (Tabel 4). Koefisien keragaman genetik dalam penelitian ini berkisar antara 6.15-83.68. Koefisien keragaman terendah ditunjukkan oleh umur panen (6.15), sedangkan gabah hampa per malai menunjukkan koefisien keragaman tertinggi (83.68). Koefisien keragaman merupakan salah satu faktor penting keberhasilan seleksi. Kegiatan Seleksi akan lebih leluasa dilakukan pada karakter yang memiliki keragaman genetik luas serta dapat digunakan untuk perbaikan genotipe (Herawati et al., 2009)

Pendugaan heritabilitas merupakan parameter penting karena dapat membantu pemulia untuk menentukan karakter yang mewariskan karakternya lebih tinggi (Akhtar et al., 2011). Semua karakter yang diamati pada penelitian ini memiliki nilai heritabilitas tinggi berkisar antara 90.7299.58\% (Tabel 4). Nilai heritabilitas yang tinggi akan membantu kegiatan seleksi berdasarkan fenotipe (Khan et al. 2009). Lebih lanjut Dhanwati et al. (2013) mengemukakan bahwa nilai heritabilitas tinggi mengindikasikan bahwa peran faktor lingkungan dalam ekspresi karakter rendah.

\section{Korelasi Antar Karakter}

Nilai koefisien korelasi dalam penelitian ini disajikan pada Tabel 5. Tinggi tanaman generatif, jumlah anakan produktif, jumlah gabah isi, jumlah gabah total, dan kerapatan malai berkorelasi sangat nyata dan positif dengan bobot gabah per rumpun. Fiyaz et al. (2011) juga mendapatkan hasil korelasi sangat nyata antara tinggi tanaman dan jumlah anakan produktif dengan bobot gabah per rumpun. 
Tabel 4. Koefisien keragaman genetik dan nilai duga heritabilitas

\begin{tabular}{lcccc}
\hline \multirow{2}{*}{ Karakter } & KKG & Keragaman & \multicolumn{2}{c}{$\mathrm{h}^{2}{ }_{\text {bs }}(\%)$} \\
\cline { 3 - 5 } genetik & Nilai & Kriteria \\
\hline Bobot 100 butir & 9.17 & Luas & 96.95 & Tinggi \\
Bobot gabah kering per rumpun & 20.11 & Luas & 90.72 & Tinggi \\
Tinggi tanaman generatif & 18.39 & Luas & 99.58 & Tinggi \\
Jumlah anakan & 21.18 & Luas & 94.10 & Tinggi \\
Jumlah anakan produktif & 17.15 & Luas & 90.81 & Tinggi \\
Panjang malai & 10.70 & Luas & 97.77 & Tinggi \\
Jumlah gabah isi per malai & 23.75 & Luas & 97.01 & Tinggi \\
Jumlah gabah hampa per malai & 83.68 & Luas & 97.72 & Tinggi \\
Umur berbunga & 7.18 & Luas & 99.20 & Tinggi \\
Jumlah gabah per malai & 28.31 & Luas & 98.46 & Tinggi \\
Kerapatan malai & 26.32 & Luas & 98.60 & Tinggi \\
Umur panen & 6.15 & Luas & 99.30 & Tinggi \\
\hline
\end{tabular}

keterangan: $\mathrm{KKG}=$ koefisien keragaman genetik; $\mathrm{h}^{2}{ }_{\mathrm{bs}}=$ heritabilitas arti luas

Karakter jumlah gabah isi per malai berkorelasi negatif dan nyata dengan bobot 100 butir (-0.39) (Tabel 5). Semakin tinggi jumlah gabah isi per malai maka kebutuhan sink akan semakin tinggi, namun keterbatasan source dalam menyediakan kebutuhan sink membuat pengisian tidak maksimal. Investigasi Bu-Hong (2006) pada hubungan source-sink padi hibrida menemukan bahwa semakin tinggi jumlah gabah dan hasil, pengisian biji menjadi lebih buruk dan persentase pembentukan biji bernasnya semakin rendah.

Hubungan source-sink juga terlihat dari korelasi antara jumlah gabah total dan jumlah gabah hampa (berkorelasi nyata dan positif 0.74 ) (Tabel 5). Semakin tinggi jumlah gabah total, semakin tinggi gabah hampa per malai. Huang et al. (2012) melaporkan bahwa pengisian biji yang rendah dapat terjadi pada kultivar yang memiliki jumlah gabah per malai tinggi seperti pada padi hibrida super.

Kerapatan malai merupakan salah satu karakter yang menentukan seberapa banyak jumlah gabah per malai. Semakin rapat malai, maka jumlah gabah per malai akan semakin banyak. Hal ini terkonfirmasi berdasarkan nilai korelasi, yaitu nyata positif dengan gabah isi (0.82), jumlah gabah hampa (0.66), jumlah gabah total (0.93) dan bobot per rumpun (0.51) (Tabel 5).

Jumlah anakan produktif berkorelasi negatif dengan gabah isi dan gabah total (-0.42 dan -0.32) (Tabel 5). Safitri et al. (2011) juga melaporkan bahwa peningkatan jumlah anakan produktif berbanding terbalik dengan jumlah gabah

Tabel 5. Korelasi antar karakter pengamatan galur dihaploid DH0 asal kultur antera

\begin{tabular}{|c|c|c|c|c|c|c|c|c|c|c|c|}
\hline & B100 & BR & TG & JA & JAP & PM & GI & $\mathrm{GH}$ & UB & GT & KM \\
\hline $\mathrm{BR}$ & $-0.09 \mathrm{tn}$ & & & & & & & & & & \\
\hline TG & $-0.12 \mathrm{tn}$ & $0.39 * *$ & & & & & & & & & \\
\hline JA & $-0.02 \mathrm{tn}$ & $0.26 \mathrm{tn}$ & $-0.18 \mathrm{tn}$ & & & & & & & & \\
\hline JAP & $0.04 \mathrm{tn}$ & $0.41 * *$ & $-0.16 \mathrm{tn}$ & $0.87 * *$ & & & & & & & \\
\hline PM & $0.07 \mathrm{tn}$ & $0.18 \mathrm{tn}$ & $0.62 * *$ & $-0.28 *$ & $-0.30 *$ & & & & & & \\
\hline GI & $-0.39 * *$ & $0.54 * *$ & $0.38 * *$ & $-0.43 * *$ & $-0.42 * *$ & $0.35^{*}$ & & & & & \\
\hline $\mathrm{GH}$ & $-0.03 \mathrm{tn}$ & $0.19 \mathrm{tn}$ & 0.14 tn & $-0.13 \mathrm{tn}$ & $-0.05 \mathrm{tn}$ & $0.29 *$ & $0.28 *$ & & & & \\
\hline UB & $0.21 \mathrm{tn}$ & $-0.19 \mathrm{tn}$ & $0.29 \mathrm{tn}$ & $-0.01 \mathrm{tn}$ & $-0.10 \mathrm{tn}$ & $0.26 \mathrm{tn}$ & $-0.21 \mathrm{tn}$ & $0.03 \mathrm{tn}$ & & & \\
\hline GT & $-0.29 *$ & $0.48 * *$ & $0.34 * *$ & $-0.38 * *$ & $-0.32 *$ & $0.40 * *$ & $0.86^{* *}$ & $0.74 * *$ & $-0.13 \mathrm{tn}$ & & \\
\hline $\mathrm{KM}$ & $-0.37 * *$ & $0.51 * *$ & $0.14 \mathrm{tn}$ & $-0.27 *$ & $0.20 \mathrm{tn}$ & $0.05 \mathrm{tn}$ & $0.82 * *$ & $0.66^{* *}$ & $-0.25 \mathrm{tn}$ & $0.93 * *$ & \\
\hline UP & $0.20 \mathrm{tn}$ & $-0.14 \mathrm{tn}$ & $0.29 *$ & $0.02 \mathrm{tn}$ & $-0.08 \mathrm{tn}$ & $0.28 *$ & $-0.17 \mathrm{tn}$ & $0.05 \mathrm{tn}$ & $0.98 * *$ & $-0.09 \mathrm{tn}$ & $-0.22 \mathrm{tn}$ \\
\hline
\end{tabular}

Keterangan: Keterangan: $\mathrm{TG}=$ tinggi generatif; $\mathrm{JA}=$ jumlah anakan; $\mathrm{JAP}=$ jumlah anakan produktif; $\mathrm{PM}=$ panjang malai; $\mathrm{PM}=$ panjang malai; $\mathrm{GI}=$ jumlah gabah isi, $\mathrm{GH}=$ jumlah gabah hampa; $\mathrm{UB}=$ umur berbunga; $\mathrm{GT}=$ gabah total; $\mathrm{KM}=$ kerapatan malai; UP $=$ umur panen. ${ }^{* *}=$ sangat nyata; $*$ nyata; $\mathrm{tn}=$ tidak nyata pada $\alpha 5 \%$ 
total. Hal ini mungkin disebabkan galur-galur tersebut cenderung memiliki panjang malai pendek. Hal ini terlihat dari korelasi antara jumlah anakan produktif dan panjang malai (-0.30), dan korelasi antara panjang malai dengan jumlah gabah total dan jumlah gabah isi (masing-masing 0.40 dan 0.35 ).

\section{KESIMPULAN}

Dari 48 galur dihaploid terdapat 20 galur yang memiliki bobot per rumpun setara Inpago 10, 30 galur setara Ciherang, dan 42 galur setara Inpari 18. Galur-galur DH0 dalam penelitian ini memiliki keragaman luas dengan nilai heritabilitas tinggi (lebih dari 90\%). Bobot per rumpun berkorelasi positif dan sangat nyata dengan tinggi generatif, jumlah anakan produktif, jumlah gabah isi, jumlah gabah total, dan kerapatan malai.

\section{DAFTAR PUSTAKA}

Anupam, A., J. Imam, S.M. Quatadah, A. Siddaiah, S.P. Das, M. Variar, N.P. Mandal. 2017. Genetic diversity analysis of rice germplasm in Tripura State of Northeast India using drought and blast linked markers. Rice Sci. 24:10-20.

Akhtar, N., M.F. Nazir, A. Rabnawaz, T. Mahmood, M.E. Safdar, M. Asif, A. Rehman. 2011. Estimation of heritability, correlation and path coefficient analysis in fine grain rice (Oryza sativa L.). J. Animal Plant Sci. 21:660-664.

Akhmadi, G., B.S. Purwoko, I.S. Dewi. D. Wirnas. 2017. Pemilihan karakter agronomi untuk seleksi pada galur-galur padi dihaploid hasil kultur antera. J. Agron. Indonesia 45:1-8.

Bagati, S., A.K. Singh, R.K. Salgotra, R. Bhardwaj, M. Sharma, S.K. Rai, A. Bhat. 2016. Genetic variability, heritability, and correlation coefficients of yield and its component traits in Basmati rice (Oryza sativa L.). SABRAO J. Breeding Genet. 48:445-452.

Bradshaw, J.E. 2017. Plant breeding: past, present and future. Euphytica.doi. 101007/s10681-0161815-y.

Bu-Hong, Z., W. Peng, Z. Hong-Xi, Z. Qing-Sen, Y. Jiang-Chang. 2006. Source-sink and grain filling characteristics of two-line hybrid rice Yangliangyou. Rice Sci. 13:34-42.

Dewi, I.S., A.C. Trilaksana, T. Koesoemaningtyas, B.S. Purwoko. 2009. Karakterisasi galur haploid ganda hasil kultur antera. Buletin Plasma Nutfah 15:1-12.

Dewi, I.S., B.S. Purwoko. 2012. Kultur antera untuk percepatan perakitan varietas padi di Indonesia. Jurnal AgroBiogen 8:78-88.
Dewi, I.S., M. Syafii, B.S. Purwoko, W.B. Suwarno. 2017. Efficient indica rice anther culture derived from three-way crosses. SABRAO J. Breeding Genet. 49:336-345.

Dhanwani, R.K., A.K. Sarawagi, A. Solanki, J.K. Towari. 2013. Genetic variability analysis for various yield attributing and quality traits in rice (Oryza sativa L.). The Bioscan. 8:1403-1407.

[FAO] Food and Agriculture Organization of the United Nations. 2014. FAO Statistical Yearbook 2014. Bangkok: FAO Regional Office for Asia and the Pasific.

Fiyaz, A.R., K.T. Ramya, A. Chikkalingaiah, B.C. Ajay, C. Gireesh, R.S. Kulkarni. 2011. Genetic variability, correlation and path coefficient analysis studies in rice (Oryza sativa L.) under alkaline soil condition. Electronic J. Plant Breeding 2:531-537.

Gunarsih, C., B.S. Purwoko, I.S. Dewi, M. Syukur. 2016. Regenerasi dan aklimatisasi kultur antera enam persilangan F1 padi sawah. J. Agron. Indonesia 44:133-140.

Herawati, R., B.S. Purwoko, I.S. Dewi. 2009. Keragaman genetik dan karakter agronomi galur haploid ganda padi gogo dengan sifat-sifat padi tipe baru hasil kultur antera. J. Agron. Indonesia 37:87-94.

Herawati, R., B.S. Purwoko, I.S. Dewi. 2010. Characterization of doubled haploid derived from anther culture for new type upland rice. J. Agron. Indonesia 38:170-176.

Huang, M., Y. Zou, P. Jiang, B. Xia, A. Xiao. 2012. Performance of super hybrid rice cultivars grown under no-tillage and direct seedling. Sci. Agric. 69: 103-107.

[IRRI] International Rice Research Institute. 2002. Standard Evaluation System for Rice. Manila (PH): INGERIRRI.

Kartina, N., B.P. Wibowo, I.A. Rumanti, Satoto. 2017. Korelasi hasil gabah dan komponen hasil padi hibrida. Penelitian Tanaman Pangan 1:11-19.

Kato, Y., K. Katsura. 2014. Rice adaptation to aerobic soils: Physicological consideration and implication for agronomy. Plant Prod. Sci. 17:1-12.

Khan, A.S., M. Imran, M. Ashfaq. 2009. Estimation of genetic variability and correlation for grain yield component in rice (Oryza sativa L.). AmericanEurasian J. Agric. Eviron. Sci. 6:585-590. 
Lang, N.T., B.P. Tam, N.V. Hieu, C.T. Nha, A. Ismail, R. Reinke, B.C. Buu. 2014. Evaluation of rice landraces in Vietnam using SSR markers and morphological characters. SABRAO J. Breeding Genet. 46:1-20.

Leung, H., C. Raghavan, B. Zhou, R. Olivia, R. Choi, V. Lacorte, M.L. Jubay, C.V. Cruz, G. Gregorio, R.K. Singh, V.J. Ulat, F.N. Borja, R. Mauleon, N.N. Alexandrov, L. McNally, R.S. Hamilton. 2015. Allele mining and enhanced genetic recombination for rice breeding. Rice. 8(34). doi:10.1186/s12284015-0069-y.

Mishra, R., G.J. Rao. 2016. In-vitro androgenesis in rice: advantages, constraints and future prospects. Rice Sci. 23:57-68.

Mishra, R., G.J.N. Rao, R.N. Rao, P. Kaushal. 2015. Development and characterization of elite double haploid lines from two indica rice hybrids. Rice Sci. 22:290-299.

Pinaria, A., A. Baihaki, R. Setiamihardja, A.A. Darajat. 1995. Variabilitas genetik dan heritabilitas karakterkarakter biomassa 53 genotipe kedelai. Zuriat. 6:8892.
Safitri, H., B.S. Purwoko, I.S. Dewi. B. Abdullah. 2011. Korelasi dan sidik lintas karakter fenotipik galur-galur padi haploid ganda hasil kultur antera. Wydiariset 14:295-304.

Sasmita, P. 2001. Kultur antera padi gogo dan F1 terpilih hasil persilangan kultivar dengan aksesi toleran naungan. Tesis. Sekolah Pasca Sarjana. Institut Pertanian Bogor. Bogor.

Seck, P.A., A. Diagne, S. Mohanty, M.C.S Wopereis. 2012. Crops that feed the world 7: Rice. Food Sec. 4:7-24.

Silva, T.D. 2010. Indica rice anther culture: can the impasse be surpassed?. Plant Cell Tiss Organ Cult. 100:1-11.

Singh, R.K., B.D.Chaudhary. 1979. Biometrical Method in Quantitative Genetik Analysis. New Delhi (IDA).

Stanfield, W.D. 1983. Theory and Problems of Genetics, $2^{\text {nd }}$ edition. Schain's Outline Series. New Delhi (IN): Mc. Graw-Hill.

Widyastuti, Y., Satoto, I.A. Rumanti. 2015. Performance of promising hybrid rice in two different elevation of irrigated lowland in Indonesia. Agrivita 37:169-177. 